\title{
Effect of boron addition on mechanical properties of Fe-Ni-Mo-B-C sintered alloys
}

\author{
Shigeki EGASHIRA*, Takashi SEKIYA ${ }^{* *}$, Tomoyuki UENO* ${ }^{*}$ and Masahiro FUJII** \\ * Advanced Materials Laboratories, Sumitomo Electric Industries, Ltd. \\ 1-1-1 Koyakita, Itami-shi, Hyogo 664-0016, Japan \\ Email: egashira-shigeki@sei.co.jp \\ ** Analysis Technology Research Center, Sumitomo Electric Industries, Ltd. \\ 1-1-1 Koyakita, Itami-shi, Hyogo 664-0016, Japan \\ *** Graduate School of Natural Science and Technology, Okayama University \\ 3-1-1 Tsushima-naka, Kita-ku, Okayama-shi, Okayama 700-8530, Japan
}

Received: 10 June 2019; Revised: 2 September 2019; Accepted: 23 October 2019

\begin{abstract}
Sintered materials are superior in productivity because of their simple process, but their mechanical properties are low. To improve the mechanical properties of sintered materials, we focus on liquid-phase sintering. In this study, we selected boron as sintering aids and evaluated on the effect of the addition quantity of boron (0-0.6 mass $\%$ ) to the mechanical properties of liquid-phase sintered and heat-treated materials. In the test range of this study, the tensile strength of material with an additional quantity of boron of 0.1 mass $\%$ showed the highest value, $1386 \mathrm{MPa}$, which is about $35 \%$ higher compared to the tensile strength of material without adding boron. On the other hand, materials with an additional quantity of boron of $0.2 \mathrm{mass} \%$ or higher showed higher-density than material with an additional quantity of boron of $0.1 \mathrm{mass} \%$, but both their elongation and tensile strength were significantly decreased. The precipitates changed between the boundary of the quantity of boron added of 0.1 and that of 0.2 mass $\%$. Only $\mathrm{Fe}_{23} \mathrm{~B}_{6}$ was formed in the material with the boron addition amount of 0.1 mass $\%$ or less, and $\mathrm{Fe}_{23} \mathrm{~B}_{6}$ and $\mathrm{Fe}_{2} \mathrm{~B}$ were formed in the material with the boron addition amount of 0.2 mass $\%$ or more. By cross-sectional observation of the test specimen after the tensile test, it was confirmed that in the material with the boron addition amount of 0.2 mass $\%$ or more cracks occurred and propagated at the $\mathrm{Fe}_{23} \mathrm{~B}_{6} / \mathrm{Fe}_{2} \mathrm{~B}$ interface and finally resulted in fracture. In the material with the boron addition amount of 0.1 mass $\%$, however, such a fracture was not confirmed. The phenomena could be explained the fact that the mechanical properties were sharply changed between the quantity of boron added of 0.1 mass $\%$ and 0.2 mass $\%$. The existence of $\mathrm{Fe}_{23} \mathrm{~B}_{6} / \mathrm{Fe}_{2} \mathrm{~B}$ interface would significantly affect the strength of the liquid-phase sintered materials.
\end{abstract}

Keywords : Powder metallurgy, Liquid phase sintered steel, Boron, Mechanical property, Tensile strength

\section{Introduction}

In high-load gear materials such as automobile transmission gears, wrought steel are usually used. However, manufacturing of gears using this method is expensive because many processes are needed. Therefore, simplification of manufacturing is needed in the industry. Sintered gears are superior in productivity because of the simple production process, and have good industrial characteristics in terms of production costs. However, the sintered gears produced by the usual press forming contain many pores inside and, therefore, their strength is insufficient (Miura et al., 2010a), and they cannot be applied to high-load gears. Therefore, many studies have been done concerning enhancing the strength of the sintered parts. For example, there are reports saying that high fatigue strength is obtained by the method in which densifying all material by HIP (Hot Isostatic Pressing) (Yoshida et al., 1995) or the 2P-2S (2 Press-2 Sinter) (Seki and Fujii, 2017; Skoglund et al., 2001) or by the method in which the gear surface is densified by surface rolling (Takemasu 
et al., 2010; Miura et al., 2010b). However, because the production processes increase with these methods, the merit of high-productivity by applying the powder metallurgy processing is severely affected.

We have focused on the liquid-phase sintering method, which can densify sintered material without using secondary processing, as a high-strengthening method for sintered materials. For example, Selecká et al. (2003) reported concerning the mechanical properties of liquid-phase 'as-sintered' material of the Fe-2Ni-0.5Mo-C-B alloys, that they obtained the result of improvement of the tensile strength by increasing the quantity of boron added. On the other hand, there were few reports concerning the mechanical properties and fatigue strength of 'sintered and heat-treated' materials, which are important material properties in the strength design of the gears. In this study, we have researched the effect of the addition of boron on the mechanical properties and microstructure of the 'sintered and heat-treated' material of Fe-1.8Ni- $0.5 \mathrm{Mo}-$ $0.3 \mathrm{C}$, which is the typical steel used in the structure of machines.

\section{Experimental procedure}

\subsection{Test specimens}

We mixed the Fe-20mass\%B powder and the graphite powder with the Fe-1.80mass\%Ni-0.52mass\%Mo$0.21 \mathrm{mass} \% \mathrm{Mn}$ prealloyed powder and prepared 6 kinds of mixed powder with different quantities of boron added. Table 1 shows the chemical composition of each mixed powder. These values are calculated from the mixing ratio of raw materials. Each mixed powder was compacted in the shape of tensile test specimen as shown in Fig.1 (JPMAM04-1992 No.1) with die wall lubrication to make their density $7.0 \mathrm{~g} / \mathrm{cm}^{3}$. Then, sintered $(1523 \mathrm{~K} \times 3.6 \mathrm{ks})$ in an argon gas atmosphere, heat treated $(1123 \mathrm{~K} \times 10.8 \mathrm{ks})$ in a vacuum atmosphere, oil quenched $(343 \mathrm{~K})$, and tempered $(473 \mathrm{~K} \times 4.8 \mathrm{ks})$. Then, they were supplied for evaluations such as a tensile test, SEM/EDX (Scanning Electron Microscope / Energy Dispersive X-ray Spectroscopy), XRD (X-ray Diffraction), STEM (Scanning Transmission Electron Microscopy) and nano-indentation analysis.

Table1 Chemical composition of the mixed powders.

\begin{tabular}{|l|c|c|c|c|c|}
\hline \multirow{2}{*}{$\mathrm{S} / \mathrm{N}$} & \multicolumn{5}{|c|}{ Chemical composition (mass\%) } \\
\cline { 2 - 6 } & $\mathrm{Ni}$ & $\mathrm{Mo}$ & $\mathrm{Mn}$ & $\mathrm{B}$ & $\mathrm{C}$ \\
\hline 0.0B & 1.80 & 0.52 & 0.21 & 0.00 & 0.30 \\
\hline 0.05B & 1.80 & 0.52 & 0.21 & 0.05 & 0.30 \\
\hline 0.1B & 1.80 & 0.52 & 0.21 & 0.10 & 0.30 \\
\hline 0.2B & 1.79 & 0.51 & 0.21 & 0.20 & 0.30 \\
\hline 0.4B & 1.77 & 0.51 & 0.21 & 0.40 & 0.30 \\
\hline 0.6B & 1.75 & 0.51 & 0.20 & 0.60 & 0.30 \\
\hline
\end{tabular}

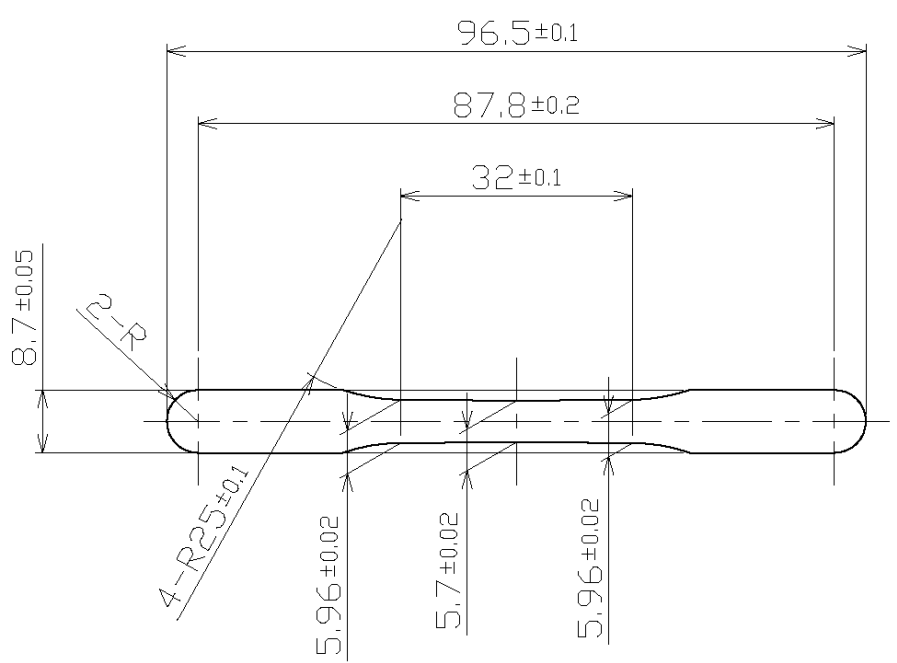

Fig.1 Shapes and dimensions of test specimen.

\subsection{Tensile test}

The tensile test was performed with a tensile testing machine (SC-100CS, Tokyo Koki Testing Machine Co., Ltd.) at room temperature. The crosshead speed was $0.5 \mathrm{~mm} / \mathrm{min}$. We measured the maximum load $P_{\max }(\mathrm{N})$ and the initial crosssectional area $A_{0}\left(\mathrm{~mm}^{2}\right)$ and calculated the tensile strength $\sigma(\mathrm{MPa})$ according to the equation (2.1). We measured the gauge length after tensile test $L_{f}(\mathrm{~mm})$, and calculated the elongation $\delta(\%)$ with the equation (2.2). The initial gauge length $L_{0}(\mathrm{~mm})$ was $25 \mathrm{~mm}$.

$$
\sigma=\frac{P_{\max }}{A_{0}}
$$




$$
\delta=\frac{L_{f}-L_{0}}{L_{0}} \times 100
$$

\subsection{Nano-indentation analysis}

The sample for nano-indentation analysis was prepared by mechanically polishing and ion milling a piece cut about $2 \mathrm{~mm}$ square from the center of the tensile test specimen. The load-displacement curve was measured by using Bruker hysitron TI 980 (Bruker Nano). Berkovich indenter was used for the indenter. The maximum load was $0.3 \mathrm{mN}$, the load time was 3 seconds, the maximum load holding time was 2 seconds, and the unload time was 3 seconds. The measurement points were determined based on the observation results of the AFM (Atomic Force Microscope) attached to the equipment. After the evaluation, the indentation was observed by SEM to determine the measurement point.

\section{Results and discussion}

\subsection{Sintered density and tensile test}

Fig.2 shows the density measurement results after sintering and Fig.3 shows the tensile test results of each material respectively. The sintered density increases according to the increase of the quantity of boron added while the tensile strength showed the maximum value in the material with a quantity of boron added of 0.1 mass $\%$. The material with a quantity of boron added of 0.1 mass $\%$ showed an increase in tensile strength of approximately $35 \%$ compared to the material without any boron added. This result verified that the addition of boron is effective for improvement of the mechanical property of the sintered and heat-treated materials. On the other hand, the material with boron of 0.2 mass $\%$ or more added showed significant elongation decrease and the tensile strength decrease. In general, since pores in the sintered material adversely affect the mechanical properties, the tensile strength of 'as-sintered' material tends to improve as the sintered density increases. For example, Selecká et al (2003) reported the mechanical properties of the liquid-phase 'as-sintered' Fe-2Ni-0.5Mo-xB-C ( $\mathrm{x}=0-0.6$ mass\%) alloys. They obtained the results of improvement of the sintered density by increasing the quantity of boron added, which accompanied the tensile strength increase. The tensile strength of the 'sintered and heat-treated' materials in this study showed the maximum value at the boron addition amount of 0.1 mass $\%$ where the sintered density was not maximum. That is, the density dependence on tensile strength differs greatly between the 'as-sintered' material of the previous study and the 'sintered and heat-treated' materials in this study.

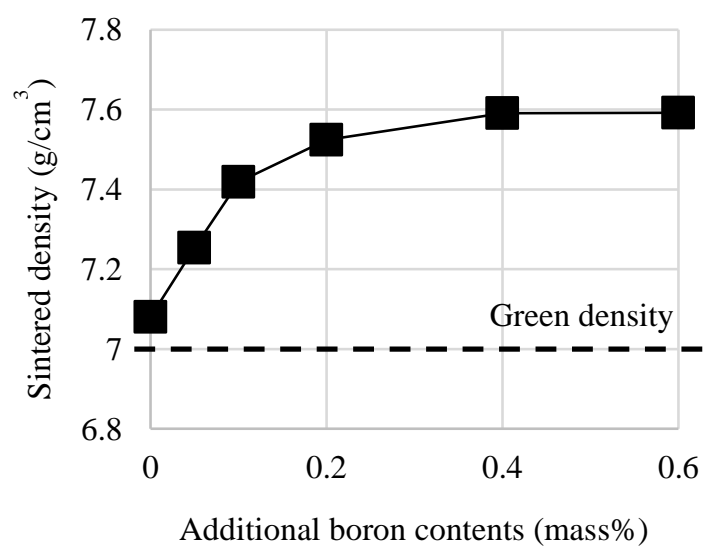

Fig.2 Effect of boron contents on the sintered density of the Fe-Ni-Mo-B-C alloys. The density of the sintered materials tended to increase accompanying an increase in the quantity of boron added. 


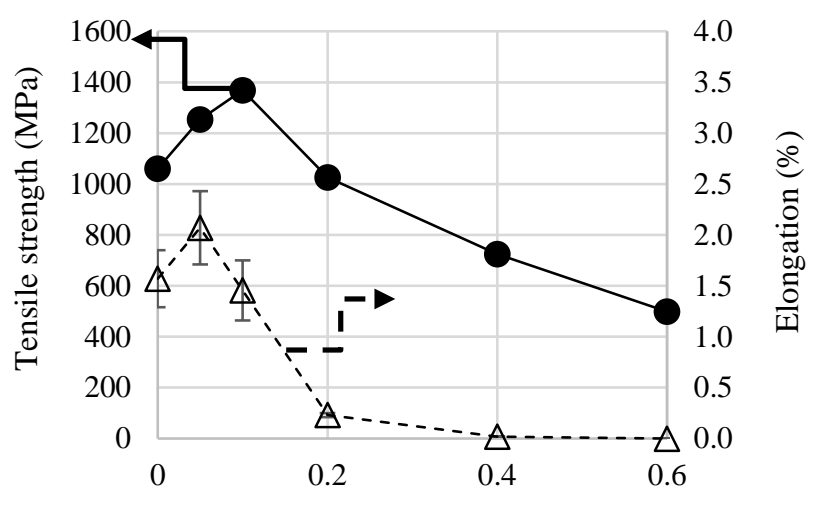

Additional boron contents (mass\%)

Fig.3 Effect of boron contents on the tensile properties of the sintered and heat-treated Fe-Ni-Mo-B-C alloys. The tensile strength of the quantity of boron added of 0.1 mass $\%$ was $35 \%$ higher compared to that of material without the addition of boron, which certifies that the minute addition of boron is effective for an increase in the mechanical property. The material with boron of 0.2 mass $\%$ or more added showed a significant elongation decrease and the tensile strength decrease tended to accompany these.

\subsection{Microstructure}

Fig.4 shows the XRD pattern of each material after heat treatment, and Fig.5 shows the graph in which the boron compound volume ratio was quantified by the RIR method according to the peak strength. By these results, at the quantity of boron added of 0.05 to 0.1 mass $\%$, only $\mathrm{Fe}_{23} \mathrm{~B}_{6}$ was formed, and at the quantity of boron added of 0.2 to 0.6 mass $\%$, $\mathrm{Fe}_{23} \mathrm{~B}_{6}$ and $\mathrm{Fe}_{2} \mathrm{~B}$ were formed. That is, the compounds differed depending on the quantity of boron added.

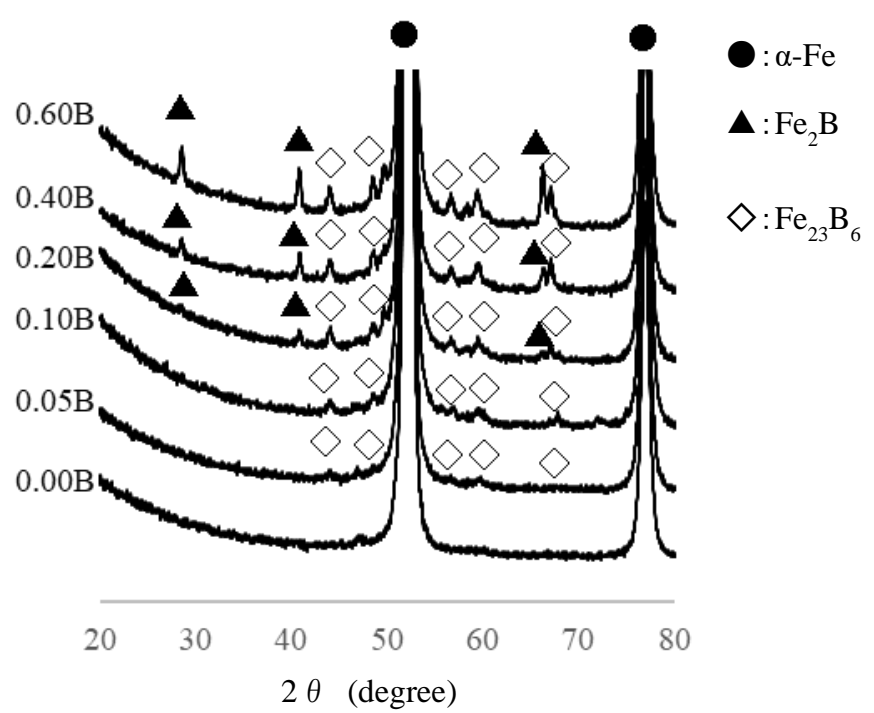

Fig.4 XRD pattern of the sintered and heat-treated Fe-Ni-Mo-B-C alloys. 


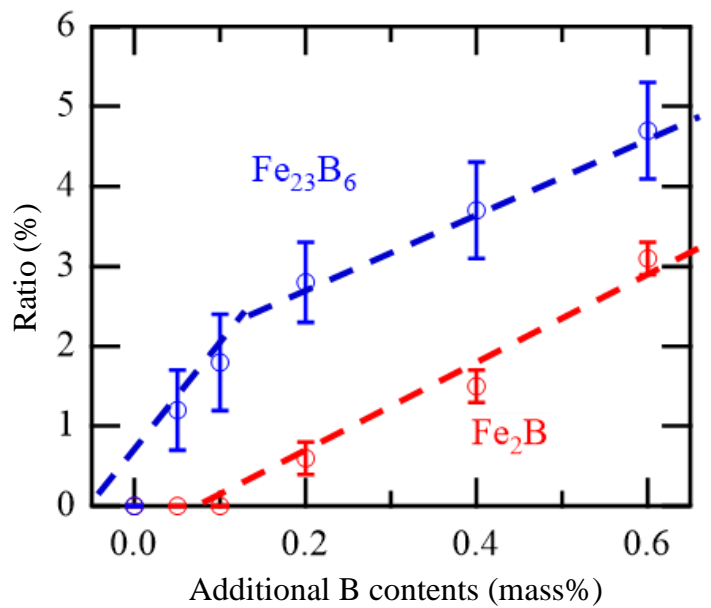

Fig.5 Quantitative analysis result of boron compound in the sintered and heat-treated Fe-Ni-Mo-B-C alloys by RIR method. And, at the boundary of the quantity of boron added of 0.1 to 0.2 mass $\%$, the boron compound formed vary. At the quantity of boron added of 0.05 to 0.1 mass\%, only $\mathrm{Fe}_{23} \mathrm{~B}_{6}$ was formed, and at the quantity of boron added of 0.2 to 0.6 mass $\%, \mathrm{Fe}_{23} \mathrm{~B}_{6}$ and $\mathrm{Fe}_{2} \mathrm{~B}$ were formed.

The kinds of boron compound change at the point of the quantity of boron added of 0.1 to 0.2 mass $\%$, which agrees with the inflection point of the tensile strength shown in Fig.3. In other words, though the 0.1B material showed high strength and elongation, the $0.2 \mathrm{~B}$ material, whose quantity of boron added is slightly increased, showed significant decrease in the tensile strength and elongation. This suggests that the formation of boron compounds such as $\mathrm{Fe}_{23} \mathrm{~B}_{6}$ and $\mathrm{Fe}_{2} \mathrm{~B}$ affects the tensile strength. The formed boron compound is discussed below. Wu et al. (2017) reported in detail the phase diagram of the $\mathrm{Fe}-1.8 \mathrm{Ni}-0.5 \mathrm{Mo}-\mathrm{xB}-0.5 \mathrm{C}$ system. It is reported that $\mathrm{Fe}_{2} \mathrm{~B}$ is the only equilibrium phase as a boron compound in the boron concentration range of $0-5$ mass $\%$, and $\mathrm{Fe}_{23} \mathrm{~B}_{6}$ does not exist on the phase diagram. In addition, $\mathrm{Fe}_{23} \mathrm{~B}_{6}$ is also reported to be a metastable phase formed when Fe-B alloys are rapidly cooled from high temperature (Mizuno et al., 2012). Therefore, in this study, it is supposed that only $\mathrm{Fe}_{2} \mathrm{~B}$, which is an equilibrium phase, was formed after sintering, and part or all of $\mathrm{Fe}_{2} \mathrm{~B}$ transformed into $\mathrm{Fe}_{23} \mathrm{~B}_{6}$ by the subsequent heat treatment.

Fig.6 shows the cross-sectional SEM image of each specimen. In all the test specimens, the matrix is the structure consisting of the tempered martensite as the main phase. And it can be understood that the precipitates are gradually formed on the network accompanying the increase in the quantity of boron added.
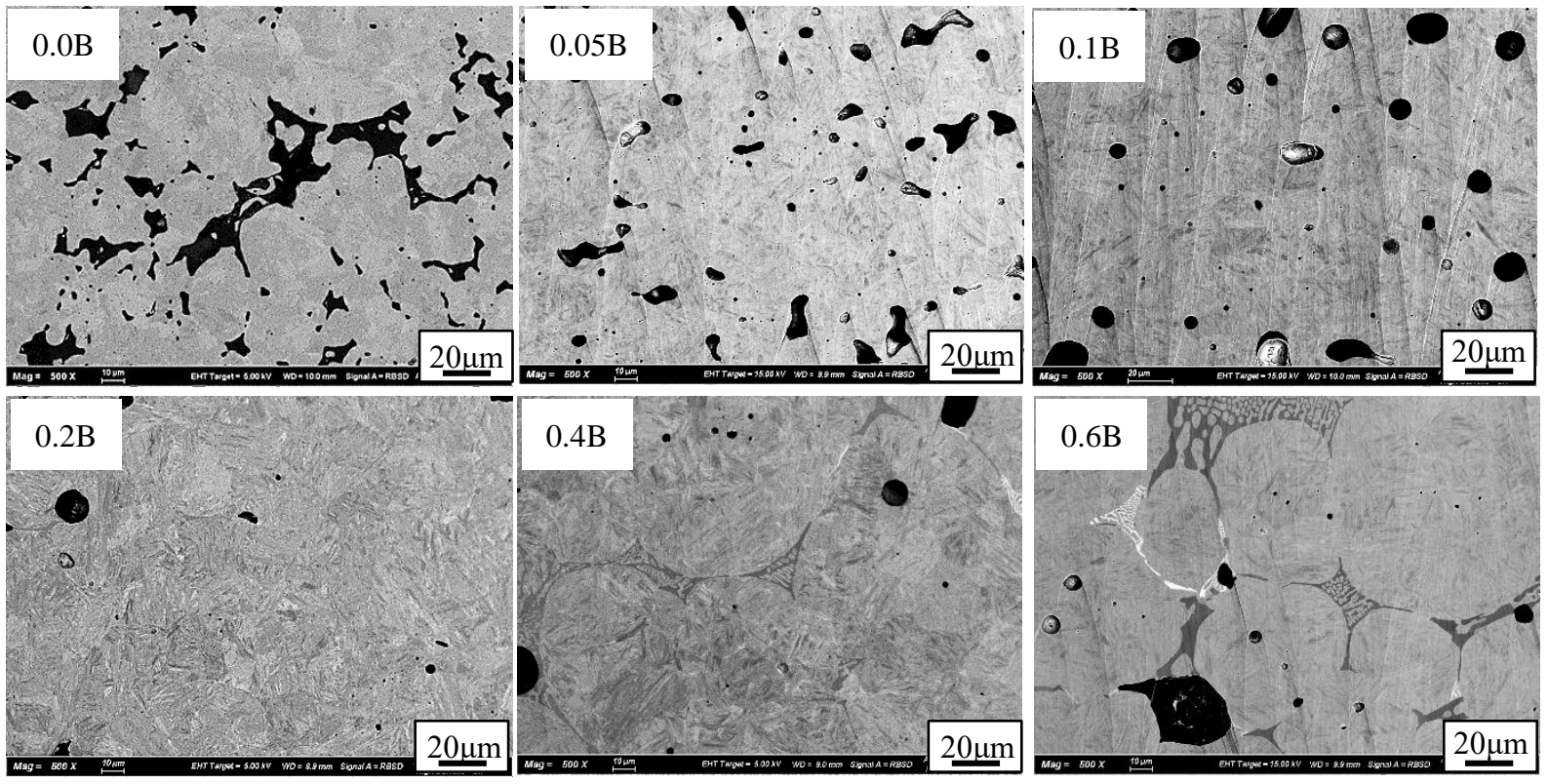

Fig.6 Cross-sectional microstructure of the sintered and heat-treated Fe-Ni-Mo-B-C alloys. In all the test specimens, the matrix is the structure consisting of the tempered martensite as the main phase. And the precipitate volume ratio is gradually increasing accompanying the increase in the quantity of boron added. 
Therefore, we conducted STEM observation for the $0.1 \mathrm{~B}$ material where only $\mathrm{Fe}_{23} \mathrm{~B}_{6}$ exists as the boron compound and investigated its existing form. Fig.7 (a) shows the cross-sectional SEM image (backscattered electron image) of the 0.1B material. Fig.7 (b) shows the STEM image of the shadow area part in the drawing cut out by FIB (Focused Ion Beam System) containing a part of the precipitate with different contrast to the matrix. Then, Fig.7 (c) shows the electron beam diffraction pattern of the precipitate. The precipitate was identified to be $\mathrm{Fe}_{23} \mathrm{~B}_{6}$ according to the lattice constant analysis of the diffraction pattern shown in Fig.7 (c). Then $0.1 \mathrm{~B}$ material would have the structure where $\mathrm{Fe}_{23} \mathrm{~B}_{6}$ is precipitated in the main phase of the tempered martensite.

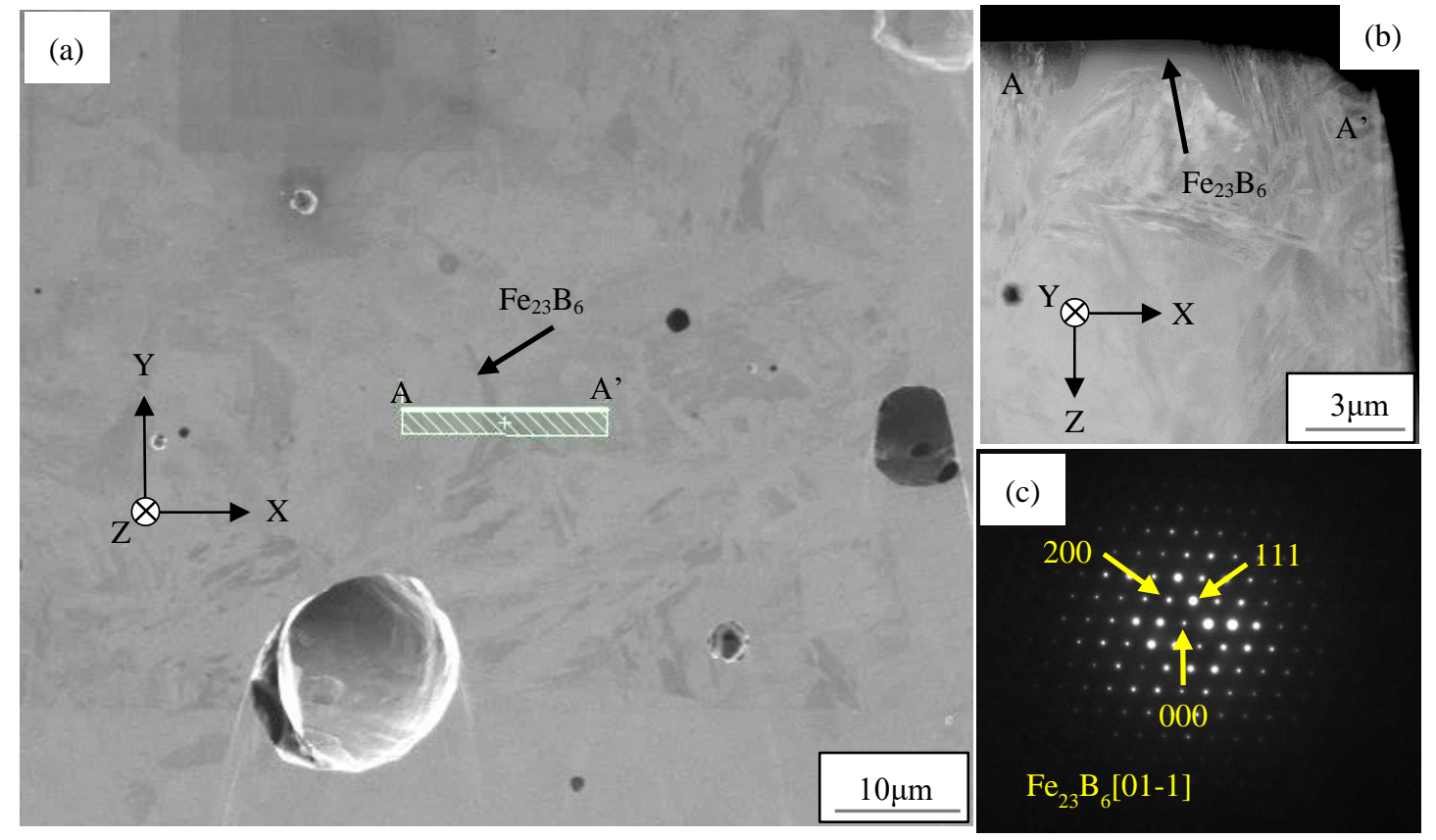

Fig.7 Cross-sectional analysis of 0.1B material. (a) SEM, (b) STEM image of the shadow area part (c) Electron beam diffraction pattern. The $0.1 \mathrm{~B}$ material is the structure where $\mathrm{Fe}_{23} \mathrm{~B}_{6}$ is precipitated in the main phase of tempered martensite.

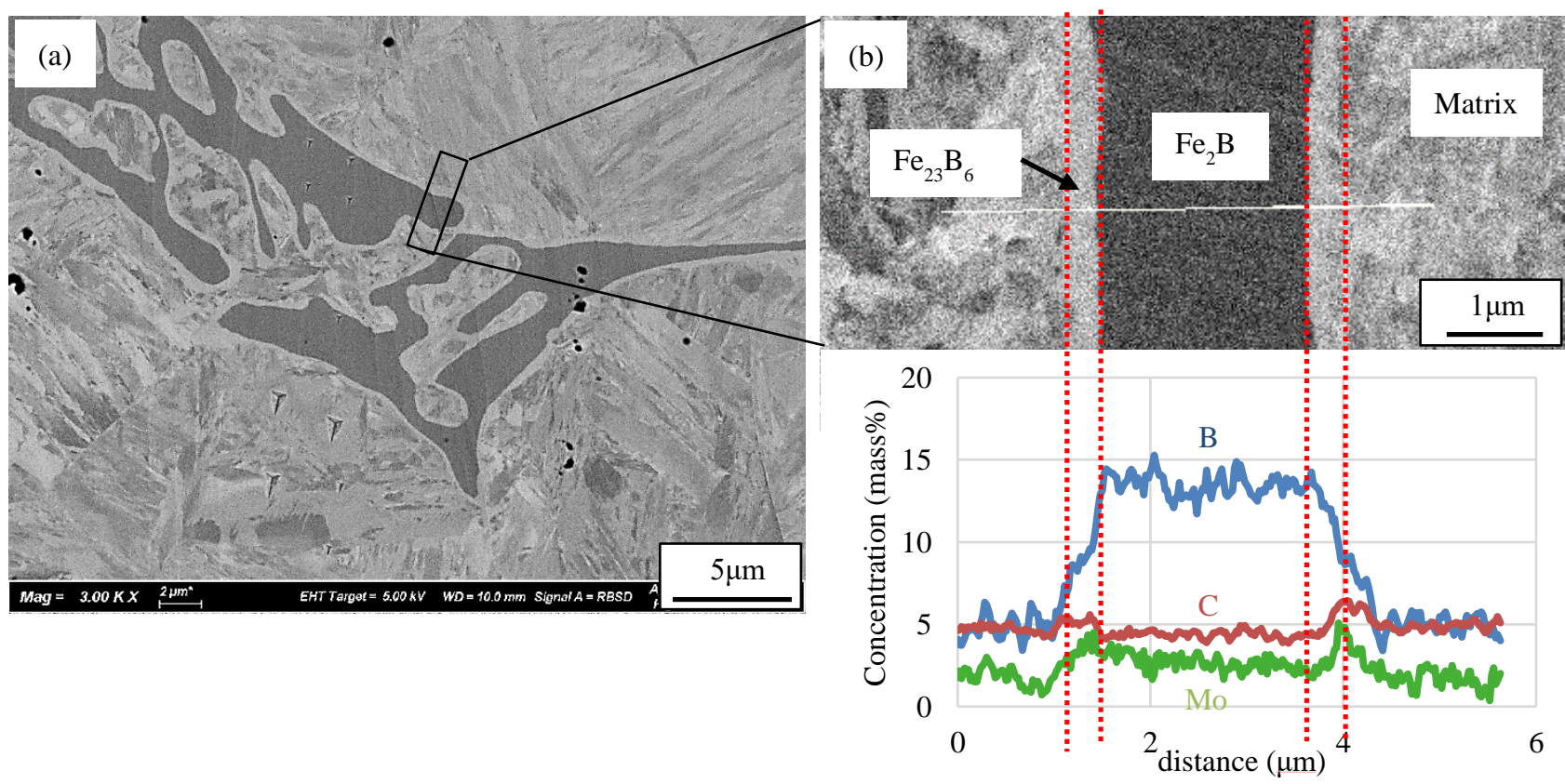

Fig. 8 Cross-sectional SEM/EDX analysis of 0.4B. The precipitate of $0.4 \mathrm{~B}$ material is the material structure where the $\mathrm{Fe}_{23} \mathrm{~B}_{6}$ fringes around the $\mathrm{Fe}_{2} \mathrm{~B}$. 
Next, Fig.8 (a) shows the cross-sectional SEM image of the enlarged precipitate of the $0.4 \mathrm{~B}$ material where both boron compound of $\mathrm{Fe}_{2} \mathrm{~B}$ and $\mathrm{Fe}_{23} \mathrm{~B}_{6}$ exist. From this $\mathrm{SEM}$ image, the precipitate consists of the black phase and the white phase surrounding it. Because in the backscattered electron image the difference in the contrast shows the different composition, it is suggested that the precipitate consists of the different two kinds of phases with different composition. Fig.8 (b) shows the results of the composition analysis of a part of the precipitate by SEM/EDX. Because both the black part and white part are of higher boron concentration than the matrix, both of them are considered to be a boron compound. According to the above-mentioned XRD results, the formed boron compound would be of two kinds: $\mathrm{Fe}_{2} \mathrm{~B}$ and $\mathrm{Fe}_{23} \mathrm{~B}_{6}$, therefore, the black high-concentration boron phase is identified to be $\mathrm{Fe}_{2} \mathrm{~B}$, and the white low-concentration boron phase to be $\mathrm{Fe}_{23} \mathrm{~B}_{6}$.

Fig.9 shows the schematic diagram of the microstructure based on the above analysis results. The formed boron compound differs, at the boron addition quantity of 0.1 to $0.2 \mathrm{mass} \%$. At the quantity of boron added of $0.1 \mathrm{mass} \%$ or lower, the material would have the microstructure where $\mathrm{Fe}_{23} \mathrm{~B}_{6}$ is precipitated in the main phase of the tempered martensite. On the other hand, at quantity of boron added of 0.2 mass $\%$ or higher, the precipitate is formed where the $\mathrm{Fe}_{23} \mathrm{~B}_{6}$ fringes around $\mathrm{Fe}_{2} \mathrm{~B}$; and, accompanying the boron addition quantity increase, the precipitate volume ratio is also increased.

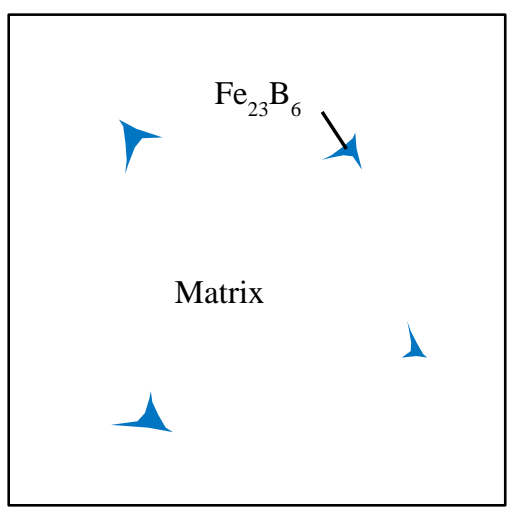

(a) $0-0.1$ mass $\% \mathrm{~B}$

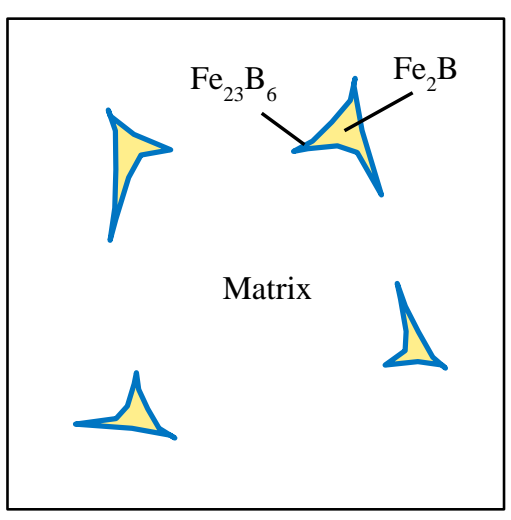

(b) $0.2-0.6 \mathrm{mass} \% \mathrm{~B}$

Fig.9 Schematic diagram of the microstructure of the sintered and heat-treated material.

\subsection{Elastic modulus of each phase}

Data for the elastic modulus and brittleness of each phase are important to consider the relationship between the mechanical properties and the microstructure. But, concerning intermetallic compounds like $\mathrm{Fe}_{2} \mathrm{~B}$ and $\mathrm{Fe}_{23} \mathrm{~B}_{6}, \mathrm{there}$ are few reports of measuring their physical properties. Therefore, in this study, the elastic modulus of each phase of the $0.1 \mathrm{~B}$ materials and the 0.4B materials were measured by the nano-indentation method (Oliver and Pharr, 1992). The nanoindentation method is a method where hardness and elastic modulus are calculated from the load-displacement curve obtained by pushing a triangular pyramid indenter into a sample and by tearing it away from the sample, which are suitable for evaluating the mechanical properties of the minute area like these samples. Fig.10 (a) and (b) are the crosssectional SEM images of the precipitate of the $0.1 \mathrm{~B}$ material and the $0.4 \mathrm{~B}$ material respectively. The triangle indentation pointed by the arrow in the image is the measuring point of each phase. Fig.10 (c) and (d) show the load-displacement curve of each formed phase of the $0.1 \mathrm{~B}$ material and the $0.4 \mathrm{~B}$ material respectively.

Firstly, focusing on the $\mathrm{Fe}_{23} \mathrm{~B}_{6}$ phase, points of discontinuity called pop-in (Wang and Ngan, 2004; Briton, 2009) for both $0.1 \mathrm{~B}$ material and $0.4 \mathrm{~B}$ material can be seen. This is specific behavior occurring at the time of the generation of cracks inside when the load of the nano-indenter is applied, which suggests that the measurement place is brittle. Because such pop-ins are not confirmed in the load-displacement curve of the $\mathrm{Fe}_{2} \mathrm{~B}$ and the matrix, $\mathrm{Fe}_{23} \mathrm{~B}_{6}$ is considered to be a more brittle phase than $\mathrm{Fe}_{2} \mathrm{~B}$ and the matrix. Fig. 11 shows the results of each phase elastic modulus calculated from the unloading curves shown in Fig.10 (c) and (d). For 0.1B material, the elastic modulus of the matrix is $230 \mathrm{GPa}$ and the elastic modulus of the $\mathrm{Fe}_{23} \mathrm{~B}_{6}$ phase is $231 \mathrm{GPa}$, which are equivalent to each other. On the other hand, for 0.4B material, the elastic modulus of the matrix is $267 \mathrm{GPa}$, and the elastic modulus of the $\mathrm{Fe}_{23} \mathrm{~B}_{6}$ phase is equivalent $278 \mathrm{GPa}$. But the elastic modulus of $\mathrm{Fe}_{2} \mathrm{~B}$ phase is $368 \mathrm{GPa}$, which is larger than the other two phases. Accordingly, the $\mathrm{Fe}_{2} \mathrm{~B}$ phase is 
considered to be the phase which is difficult to elongate compared to the matrix and the $\mathrm{Fe}_{23} \mathrm{~B}_{6}$ phases.
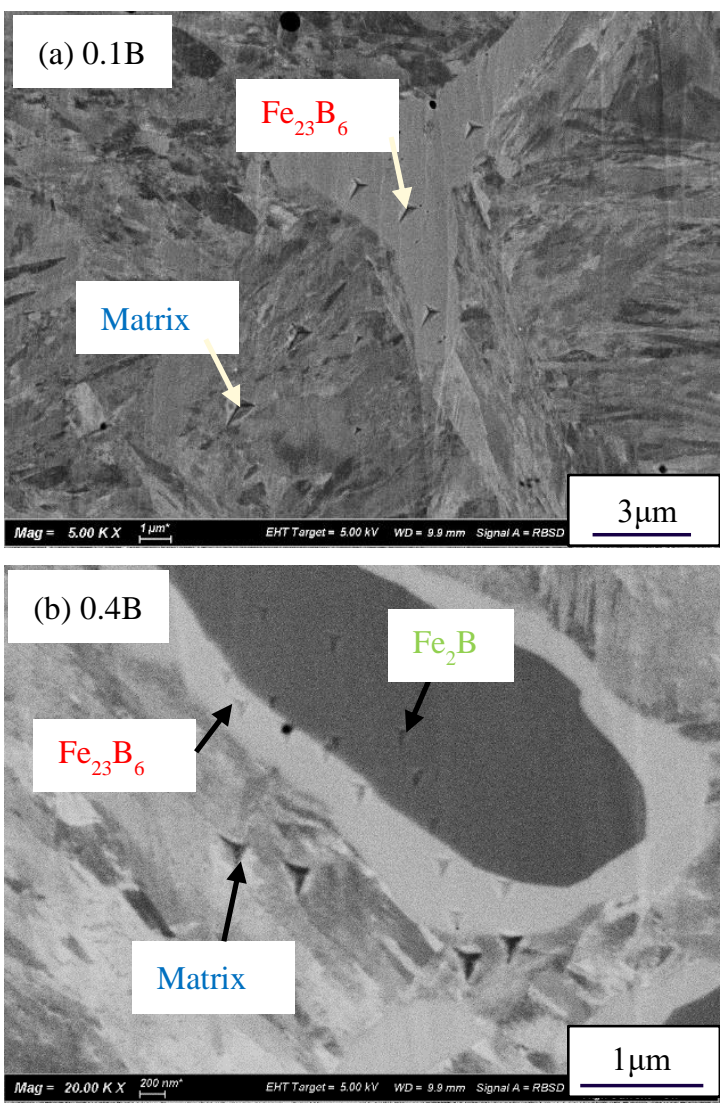

(c) $0.1 \mathrm{~B}$

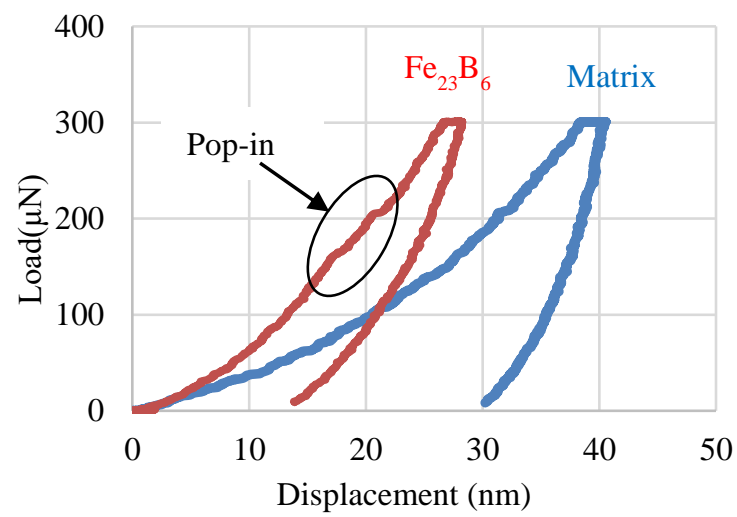

(d) $0.4 \mathrm{~B}$

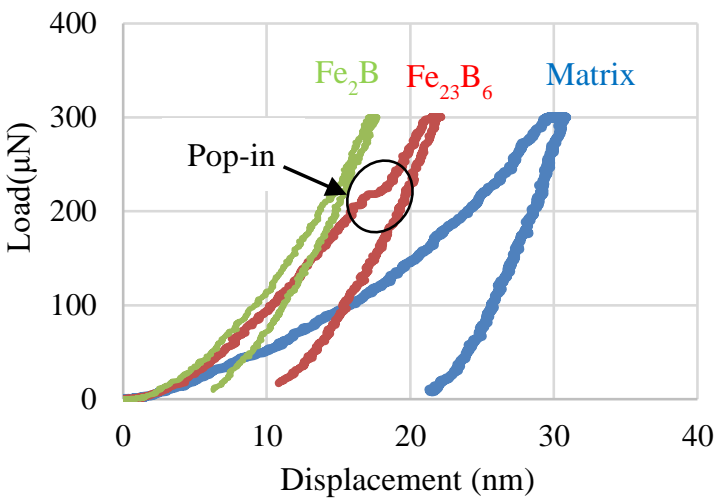

Fig.10 Load-displacement curve measurement results of each phase of $0.1 \mathrm{~B}$ material and $0.4 \mathrm{~B}$ material measured by the nano-indentation method.

(a) Nano-indenter measurement place of 0.1B material (b) Nano-indenter measurement place of 0.4B material

(c) Load-displacement curve of each phase of 0.1B material (d) Load-displacement curve of each phase of 0.4B material

In the load-displacement curve of $\mathrm{Fe}_{23} \mathrm{~B}_{6}$ phase, the discontinuity point called pop-in was confirmed. The $\mathrm{Fe}_{23} \mathrm{~B}_{6}$ phase is supposed to be a brittle phase.

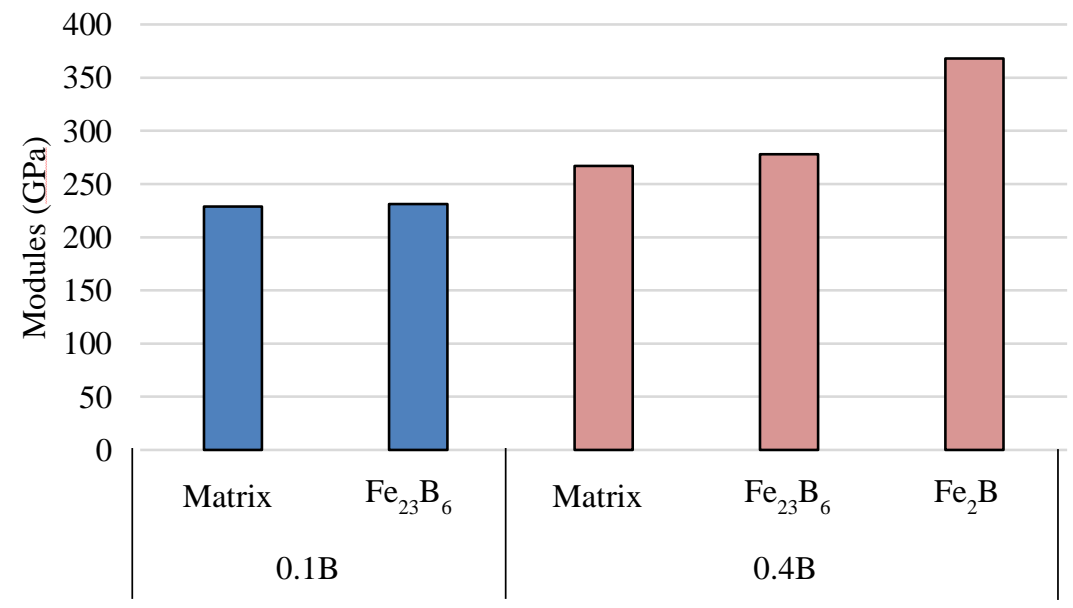

Fig.11 The elastic modulus of each phase of $0.1 \mathrm{~B}$ material and $0.4 \mathrm{~B}$ material measured by the nano-indentation method. For the $0.1 \mathrm{~B}$ material, the elastic modulus of the matrix and the $\mathrm{Fe}_{23} \mathrm{~B}_{6}$ phase are equivalent. For the $0.4 \mathrm{~B}$ material, the elastic modulus of the matrix and the $\mathrm{Fe}_{23} \mathrm{~B}_{6}$ phase are equivalent, and the elastic modulus of the $\mathrm{Fe}_{2} \mathrm{~B}$ phase is about $35 \%$ greater than those two phases. 


\subsection{Fracture mode of test specimens}

Fig.12 shows the tensile test specimen after the test and the SEM image of the A-A' cross-section at the fracture area of tensile test specimens. For the 0.1B material whose tensile strength is the largest, minute cracks are confirmed in the $\mathrm{Fe}_{23} \mathrm{~B}_{6}$ phase inside going in the stretching direction and the vertical direction, but the crack's propagation stops at around the interface with the matrix. In other words, it is supposed that the effect on the mechanical properties from the $\mathrm{Fe}_{23} \mathrm{~B}_{6}$ phase is small. On the other hand, the fracture mode of the $0.4 \mathrm{~B}$ material whose elongation is extremely small is significantly different from the fracture mode of the $0.1 \mathrm{~B}$ material, where the fracture occurs along the precipitate. Furthermore, from the enlarged photo of the precipitate, it is understood that the cracks occurred and propagated not at the precipitate inside but at the $\mathrm{Fe}_{23} \mathrm{~B}_{6} / \mathrm{Fe}_{2} \mathrm{~B}$ interface.
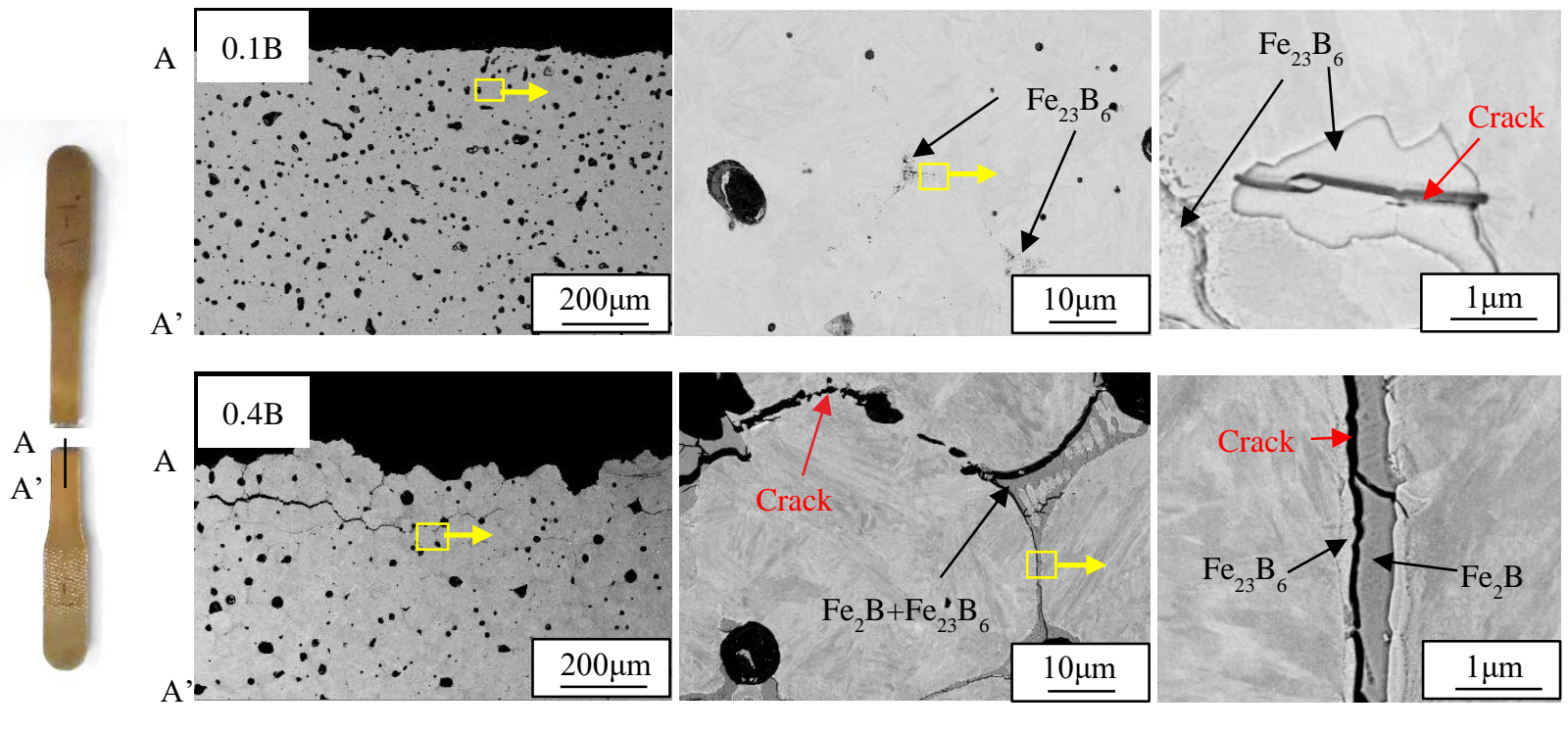

(a)


(b)

Fig.12 (a) Tensile test specimen after the test (b) Cross-section A-A' at the fracture area of tensile test specimens. Concerning the $0.1 \mathrm{~B}$ material, minute cracks occurred inside the $\mathrm{Fe}_{23} \mathrm{~B}_{6}$ phase, but they did not propagate, and $\mathrm{Fe}_{23} \mathrm{~B}_{6}$ phase has a small effect on the mechanical properties. For the $0.4 \mathrm{~B}$ material, the cracks occurred and propagated along the $\mathrm{Fe}_{23} \mathrm{~B}_{6} / \mathrm{Fe}_{2} \mathrm{~B}$ interface.

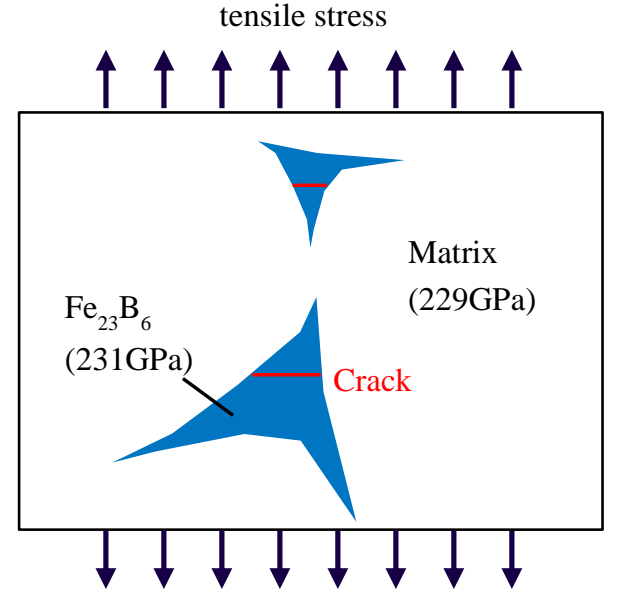

tensile stress

(a) $0-0.1$ mass $\% \mathrm{~B}$

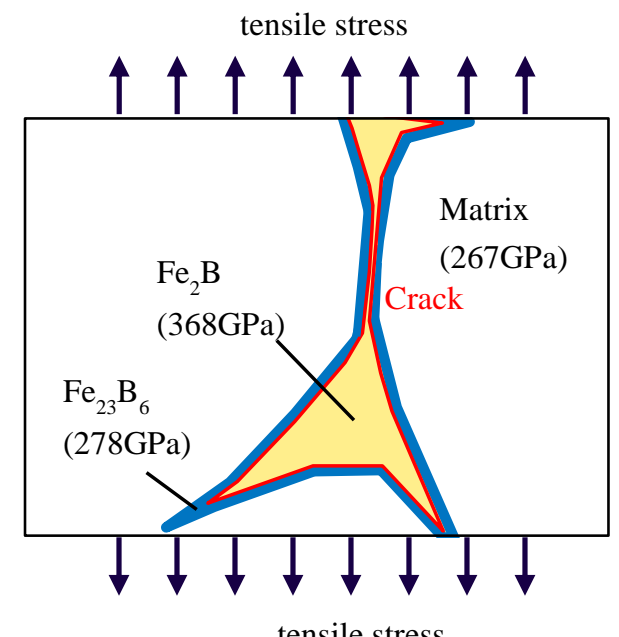

(b) $0.2-0.6 \mathrm{mass} \% \mathrm{~B}$

Fig.13 The schematic diagram of the fracture mode of each material at the time of the tensile test.

The value in ( ) is the elastic modulus of each phase. 
Fig.13 shows the schematic diagram showing the difference in the fracture mode by the quantity of boron added at the time of the tensile test. The reason why the fracture mode is significantly different between the $0.1 \mathrm{~B}$ and the $0.4 \mathrm{~B}$ material is considered to be related to the elastic modulus and the brittleness degree of $\mathrm{Fe}_{23} \mathrm{~B}_{6}, \mathrm{Fe}_{2} \mathrm{~B}$ and the matrix. According to the nano-indenter results described above, for the $0.4 \mathrm{~B}$ material, the elastic modulus of the $\mathrm{Fe}_{23} \mathrm{~B}_{6}$ is 278 $\mathrm{GPa}$, and the elastic modulus of $\mathrm{Fe}_{2} \mathrm{~B}$ is $368 \mathrm{GPa}$, which are significantly different from each other. And therefore, it is considered that the large shear stress occurred at the $\mathrm{Fe}_{23} \mathrm{~B}_{6} / \mathrm{Fe}_{2} \mathrm{~B}$ interface at the time of tensile test. Furthermore, we consider that as $\mathrm{Fe}_{23} \mathrm{~B}_{6}$ is a brittle material, in the $0.4 \mathrm{~B}$ material, peeling-like cracks occurred and propagated along the $\mathrm{Fe}_{23} \mathrm{~B}_{6} / \mathrm{Fe}_{2} \mathrm{~B}$ interface, and the mechanical properties of $0.4 \mathrm{~B}$ material were significantly decreased. On the other hand, for the $0.1 \mathrm{~B}$ material, the elastic modulus of the $\mathrm{Fe}_{23} \mathrm{~B}_{6}$ and the matrix are almost the same. Therefore, we considered that only the brittle material of $\mathrm{Fe}_{23} \mathrm{~B}_{6}$ was broken and the cracks did not propagate further. The phenomena could be explained the fact that the mechanical properties were sharply changed between the quantity of boron added of $0.1 \mathrm{mass} \%$ and 0.2 mass $\%$. The existence of the $\mathrm{Fe}_{23} \mathrm{~B}_{6} / \mathrm{Fe}_{2} \mathrm{~B}$ interface would significantly affect the strength of the liquid-phase sintered and heat-treated materials.

\section{Conclusion}

We have researched the effect of the addition of boron on the mechanical properties and metal structure of the sintered and heat-treated material of Fe-1.8Ni-0.5Mo-0.3C, which is the typical steel used in the structure of machines, and reached the following conclusions.

(1) As shown below, the material with the quantity of boron added of 0.1 mass $\%$ increased its tensile strength by $35 \%$, while maintaining the elongation, when compared with the material without boron added. This certified that the addition of boron was effective for the mechanical property increase of the sintered and heat-treated material.

- 0.0B material : 90.7 mass \% (sintered density), $1060 \mathrm{MPa}$ (tensile strength), $1.5 \%$ (elongation)

- 0.1B material : 94.2 mass \% (sintered density), $1386 \mathrm{MPa}$ (tensile strength), $1.5 \%$ (elongation)

- 0.6B material : 96.3 mass\% (sintered density), $498 \mathrm{MPa}$ (tensile strength), $0.0 \%$ (elongation)

(2) The kinds and the precipitation forms of the formed phases changed at the boundary of the quantity of boron added of 0.1 to 0.2 mass $\%$, and specifically the following metal structures were formed.

- 0.0 to 0.1 mass $\% \mathrm{~B}: \mathrm{Fe}_{23} \mathrm{~B}_{6}$ is precipitated in the main phase of tempered martensite.

- 0.2 to 0.6 mass $\% \mathrm{~B}$ : The main phase is martensite and the precipitate is formed where the $\mathrm{Fe}_{23} \mathrm{~B}_{6}$ fringes around $\mathrm{Fe}_{2} \mathrm{~B}$.

(3) We measured the load-displacement curve of each phase by the nano-indentation method and obtained the result, where the elastic modulus of the $\mathrm{Fe}_{23} \mathrm{~B}_{6}$ phase was almost the same compared to the matrix, and the elastic modulus of the $\mathrm{Fe}_{2} \mathrm{~B}$ phase was higher than those of these phases. Also, for the $\mathrm{Fe}_{23} \mathrm{~B}_{6}$ phase, points of discontinuity called "pop-in" was confirmed at this load-displacement curve, which suggested the phase was a brittle phase.

(4) By cross-section observation of the test specimen after the tensile test, it was judged that in the 0.4B material cracks occurred and propagated in the shape of peeling-off of the $\mathrm{Fe}_{23} \mathrm{~B}_{6} / \mathrm{Fe}_{2} \mathrm{~B}$ interface and finally resulted in fracture. In the material with the boron addition amount of 0.1 mass $\%$, however, such a fracture was not confirmed. The phenomena could be explained the fact that the mechanical properties were sharply changed between the quantity of boron added of 0.1 mass $\%$ and 0.2 mass $\%$. The existence of the $\mathrm{Fe}_{23} \mathrm{~B}_{6} / \mathrm{Fe}_{2} \mathrm{~B}$ interface would significantly affect the strength of the liquid-phase sintered and heat-treated materials.

We aim to eventually apply this material for high-load gear and we will conduct fatigue strength evaluation and gear fatigue strength evaluation in conditions similar to those of real machine use.

\section{References}

Briton, T.B. Randman, D. and Wilkinson, A.J., Nanoindentation study of slip transfer phenomenon at grain boundaries, Journal of Materials Research, Vol.24, No.3 (2009), pp.607-615.

Miura, H. Tsumori, F. Nakahara, Y. Tokuoka, T. and Nishioka, T., Effect of powder type on the rolling contact fatigue 
strength of 4600 sintered alloy steels, Journal of Japan Society of Powder and Powder Metallurgy, Vol.57, No.6 (2010a), pp.419-423.

Miura, H. Tsumori, F. Hamamoto, S. Komoto, K. and Unami, S., Improvement of the contact fatigue strength by rolling of sintered ferrous alloy rolle $-2^{\text {nd }}$ report-, Journal of Japan Society of Powder and Powder Metallurgy, Vol.57, No.6 (2010b), pp.430-434.

Mizuno, A. Watanabe, M. and kohara, S., Time-resolved X-ray diffraction measurement during containerless solidification processes of high-temperature undercooled melts, Journal of the Japanese Association for Crystal Growth, Vol.39, No.1 (2012), pp.37-41.

Oliver, W.C. and Pharr, G.M., An improved technique for determining hardness and elastic modulus using load and displacement sensing indentation experiments, Journal of Materials Research, Vol.7, No.6 (1992), pp.1564-1583.

Seki, M. and Fujii, M., Influence of density and nickel content on fatigue strength of powder-forged gears, Journal of Advanced Mechanical Design, Systems, and Manufacturing, Vol.11, No.6 (2017), pp.1-10.

Selecka, M. Salak, A. and Danninger, H., The effect of boron liquid phase sintering on properties of Ni-, Mo- and Cralloyed structural steels, Journal of Materials Processing Technology, Vol.141, (2003), pp.379-384.

Skoglund, P. Kejzelman, M. and Hauer, I., High density PM components by high velocity compaction, Powder Metallurgy, Vol.44, No.3 (2001), pp.199-201.

Takemasu, T. Koide, T. Takeda, Y. Shinbutsu, T. Kamimura, D. Saito, K. and Nakamura, S., Surface rolling properties and surface durability of 1.5Cr-0.2Mo sintered alloy steel rollers, Journal of Japan Society of Powder and Powder Metallurgy, Vol.57, No.6 (2010), pp.424-429.

Wang, M.G. and Ngan, A.H.W., Indentation strain burst phenomenon induced by grain boundaries in niobium, Journal of Materials Research, Vol.19, No.8 (2004), pp.2478-2486.

Wu, M. Cai, W. Lin, Z. and Chang, S., Liquid phase sintering mechanism and densification behavior of boron-alloyed Fe-Ni-Mo-C-B powder metallurgy steel, Materials and Design, Vol.133, (2017), pp.536-548.

Yoshida, A. Ohue, Y. Zhang, H. Taike, K. and Sakuma, H., Surface durability of induction-hardened powder metal rollers sintered with and without HIP, Transactions of the Japan society of mechanical engineers. C, Vol.61, No.582 (1995), pp.378-385. 